\title{
TRANSFORMER DESIGN CONSIDERATIONS FOR NON-CONTINUOUS MODE, BOOST, FLYBACK CONVERTERS
}

\author{
ROBERT NAGEL \\ RECEIVFD \\ SANDIA NATIONAL LABORATORIES \\ ALBUQUERQUE, NEW MEXICO

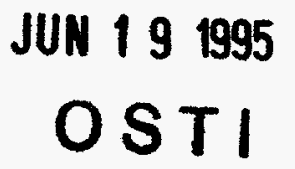

This paper presents some design considerations for small, flyback transformers used to charge energy storage capacitors to 0.1 to $5 \mathrm{KV}$ from a low voltage DC source.

The flyback circuit got it's name from use in early cathode ray tubes. A cathode ray tube uses a voltage ramp to sweep the trace across the screen. The flyback circuit was used to quickly return the voltage to zero and start another sweep. Thus the spot appeared to "flyback" between sweeps and the circuit is still referred to by this name. Flyback voltage converter circuits are excellent for low power, high voltage applications.

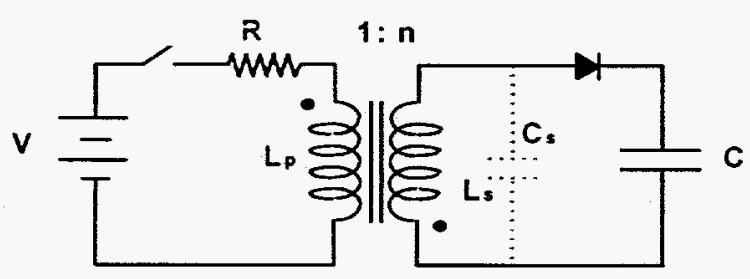

Figure 1

In a flyback converter, capacitor charging circuit (figure 1), low voltage energy is placed in an inductor $L_{p}$, then transferred to capacitor $C$. If a diode is used to prevent capacitor $\mathrm{C}$ from discharging back into the inductor $L_{s_{1}}$ a series of energy packets from the inductor can be accumulated in the capacitor. Since the volume of the inductor is related to the amount of energy $\left(1 / 2 \mathrm{LI}^{2}\right)$ stored in it, reducing the size of the converter package begins with reducing the size of the inductor. This procedure is analogous to filling a bucket (charge the capacitor to energy level $1 / 2$ $C V_{c}^{2}$ ) using many cups of water (energy $1 / 2 L_{p} l^{2}$ per cup). The smaller the cup, the more cups it takes to fill the bucket.

This work was supoorted by the United States Department of Energy under Contract DE-AC 94-94AL85000.

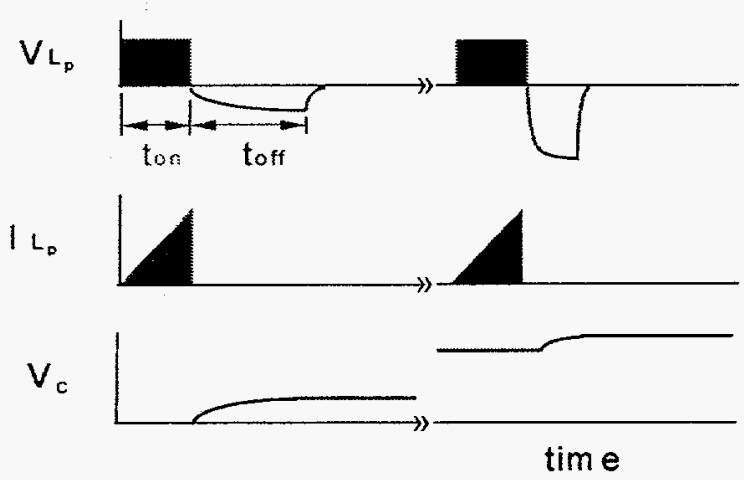

Figure 2

Figure 2 gives the time sequence of events for the circuit (figure 1). The switch is closed for time $t_{\text {on }}$, applying the source voltage $V$ to resistor $R$ and $L_{p}$. Current $I_{L p}$ increases to some peak value $I$ and energy $1 / 2 L_{p} I^{2}$ is stored in the inductor. When the switch is opened, the voltage reverses polarity, forward biasing the diode in the secondary circuit and energy flows to capacitor $C$. Note capacitor $C_{s}$ is also charged at this time. $\mathrm{C}_{\mathrm{s}}$ represents transformer secondary winding capacitance, circuit stray capacitance and some diode capacitance. This capacitance is directly across the secondary winding, is charged / discharged every cycle and puts a lower limit on $1 /\left.2 L_{p}\right|^{2}\left(1 /\left.2 L_{p}\right|^{2}>1 / 2 C_{s} V_{c}^{2}\right)$. For operation in the non-continuous mode, toff should be sufficient to let the all of the inductive energy from $L_{s}$ move to $C$ which is approximately $1 / 4$ cycle of the natural frequency given by $L_{s}$ and $C$. This approximation neglects circuit stray inductance and $C_{s}$ which are usually small compared to $L_{s}$ and C. After several cycles, $V_{c}$ is at some higher value and, following the end of $t_{o n}, V L_{p}$ rises at a rate determined by $L_{s}$ and $C_{s}$ until the diode is forward biased. The remaining energy is transferred to $C$.

The transformer in figure 1 has two functions. First it is an energy storage device and second, it serves to ratio the primary and secondary voltages. Consider the first function, energy storage in the primary loop. For a series $R, L$ and $V$ circuit, most of the energy goes to the inductor immediately following switch 


\section{DISCLAIMER}

This report was prepared as an account of work sponsored by an agency of the United States Government. Neither the United States Government nor any agency thereof, nor any of their employees, make any warranty, express or implied, or assumes any legal liability or responsibility for the accuracy, completeness, or usefulness of any information, apparatus, product, or process disclosed, or represents that its use would not infringe privately owned rights. Reference herein to any specific commercial product, process, or service by trade name, trademark, manufacturer, or otherwise does not necessarily constitute or imply its endorsement, recommendation, or favoring by the United States Government or any agency thereof. The views and opinions of authors expressed herein do not necessarily state or reflect those of the United States Government or any agency thereof. 


\section{DISCLAIMER}

Portions of this document may be illegible in electronic image products. Images are produced from the best available original document. 
closure and later, most of the energy is dissipated in the resistor. In figure 1, $R$ represents the circuit resistance, source resistance, switch resistance and primary winding resistance. Figure 3 gives the relative energy stored in the inductor divided by the total energy taken from source $V$ as a function of time measured in LR time constants. This indicates $t_{o n}$ equal to 0.1 time constant gives an energy storage efficiency of 0.83 . For efficient converter operation it is desirable to keep $t_{\text {on }}$ less than 0.1 $L_{\rho} / R$.

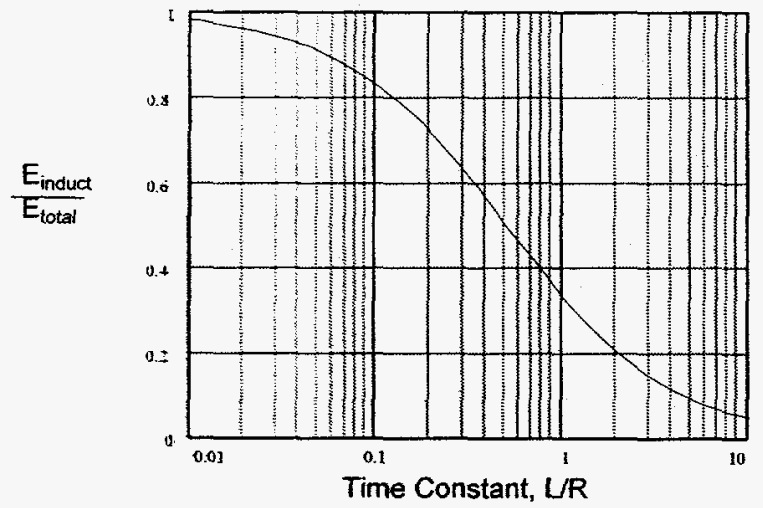

Figure 3

Figure 3 was developed using an ideal inductor. A physically realizable inductor using a magnetic core has additional constraints. Figure 4 shows the first quadrant of a hysteresis loop. When driven with a current $(l=k H)$, the core starts at $B_{r 1}$ moves to the right and builds to a higher flux density $B$ as the current increases. The two shaded areas to the left of the right side of the loop represents the energy put into the inductor. When the current drops back to zero and $B$ returns to $B_{r}, B$ follows the left side of the loop and the energy released is that shaded area on the left side of the loop. The shaded area within the loop represents energy loss in the core.

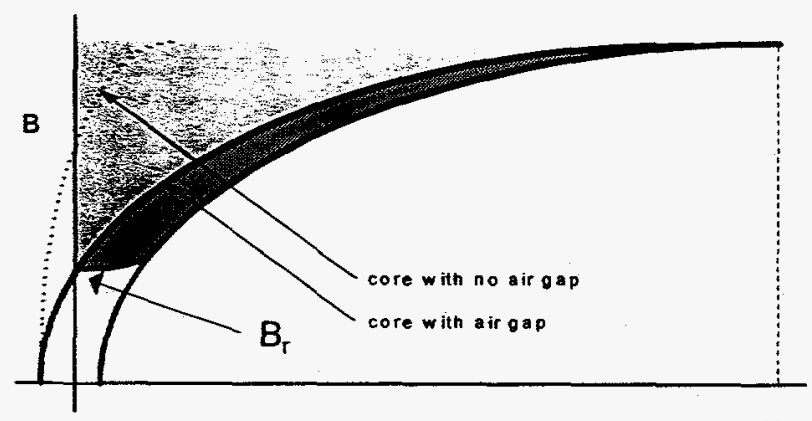

Figure 4
A dotted line is used to indicate the left side of the loop for a core without an air gap. The shaded area to left of this line represents energy stored in the core. This area is a small part of the shaded area to the left of the loop for a gapped core. The difference is due to the energy stored in the gap. Flyback converters usually use gapped cores to improve energy storage capacity of the inductor.

The second transformer function is to ratio primary and secondary voltages. This ratio is determined by input voltage, maximum output voltage and reverse voltage rating of the switch. When the switch (figure 1) is opened, the voltage across it is the secondary voltage divided by $n$ (1:n turns ratio) plus the source voltage $V$. The energy storage inductor $L_{p}$ is capable of delivering a high voltage without a secondary winding so the main reason for a secondary winding is to reduce the primary voltage for the switch. Some safety margin should be included in the switch reverse voltage rating.

A word of caution here. If there is no load on the secondary winding, the voltage can go to a high level and cause breakdown in the circuit, transformer or switch.

Following circuit analysis, transformer design then proceeds with selection of a "suitable core". Experience is a big help and reference 1 has considerable information on core selection. Ferrite pot cores or modified versions such as the RM core are good because they are commercially available with air gaps ground in the center leg to give a specified inductance per 1000 turns. Powdered, ferrous metal, toroidal cores also work well for low to moderate voltages. For high voltages, toroids generally use insulation less efficiently and have a greater production variation in winding capacitance than solenoidal wound coils. Ferrous metal cores have more stable magnetic characteristics as a functions of temperature and higher saturation flux density than ferrite cores. Ferrite cores have lower losses at high frequency, are less expensive and are available in a wider variety of shapes.

Transformer design can be an iterative procedure and computer programs are very useful in performing the repetitive calculations. At least one software program is available for designing flyback converter transformers. Following is an example of steps used in flyback transformer design. Circuit analysis gave a desired $L_{p}, n$, Imax (primary), $L_{p} / R$ 
and $\mathrm{C}_{\mathrm{s}} \max$. With this information and the initial core selected, calculate the following:

1. Primary turns $n_{D}=\left(L_{p} / L_{1000}\right)^{12} \times 1000$ where $L_{1000}$ is the core inductance per thousand turns.

2. Check the core $\Delta B$ for saturation and core loss characteristics, if necessary, select a different core and repeat steps $1 \& 2$ to keep the core from saturating or overheating.

3. Calculate the number of secondary turns $n_{s}=n_{p} \times n$ where $n \geq \max \left(V_{c}\right) /\left(V_{s w}-V\right) \cdot V_{s w}$ is the allowable switch reverse voltage.

4. Select a primary wire size for given Imax and Rmin (ton < $0.1 L_{J} / R$ ). Include wire eddy current effects in the winding resistance. Check heating effects in primary and secondary windings. Change wire size and repeat if until a satisfactory copper loss is achieved.

5. Consider the voltage gradients and temperatures to select magnet wire insulation. Add layer insulation where needed.

6. Will the wire and insulation fit on selected core? If not select a different core and repeat steps 1 through 5 .

7. Calculate secondary winding capacitance (Ref. 2) and verify $1 / 2 C_{s} V_{s}^{2}<1 / 2 L_{p}{ }^{2}$, if not, increase layer insulation in secondary winding, repeat step 6.
8. Use care in lead placement and insulation particularly for the high voltage winding. Packaging is very important for high reliability.

Minor adjustments in $\mathrm{L}_{p}$, Imax, switch reverse voltage and wire size may allow use of the next size smaller core.

Optimizing the design requires cooperation of the circuit engineer, component engineer and transformer engineer. Switch ratings have a large impact on the transformer design. Flyback converter circuits are generally used in applications below 100 watts. The basic circuit is simple but regulation circuitry can add several components.

\section{REFERENCES}

1) Colonel Wm. T. McLyman, Magnetic Core Selection for Transformers and Inductors, Marcell Dekker Inc./New York and Basel 1982. ISBN: 08247-1873-9

2) Colonel Wm. T. McLyman, Transformer and Inductor Design Handbook, Marcell Dekker Inc J New York and Basel 1978. ISBN 0-8247-6801-9 